\title{
Shear Strength of a typical soil from Manaus, Brazil, stabilized with ceramic residue additive
}

Matheus Pena da Silva e Silva ${ }^{1}$, Lucas Fernandes Santos ${ }^{1}$, Antônio Cleiton Lopes da Silva ${ }^{1}$, Consuelo Alves da Frota ${ }^{1}$

\footnotetext{
${ }^{1}$ Universidade Federal do Amazonas (UFAM), Grupo de Geotecnia - Av. General Rodrigo Octávio Jordão Ramos, 3000 Manaus, Amazonas, Brasil.

e-mail:matheuspenass@hotmail.com, lucassantosplp@gmail.com, cleiton.acls@hotmail.com,cafrot@yahoo.com.br
}

\begin{abstract}
The purpose of this study is to determine the geotechnical behavior of a clayey surface soil typical to the Manaus region (Amazonas, Brazil), when mixed with ceramic powder from brick residue produced by potteries located in the county of Iranduba, Amazonas, Brazil, and with residual sand (the reference mixture), commonly used in pavements in the region. The density of soil solids was determined, as well as particle size, consistency limits, compaction parameters and mineralogical identification using of X-ray diffraction. The following blends were made: $90 \%$ natural soil $+10 \%$ additive, $70 \%$ natural soil $+30 \%$ additive and $50 \%$ natural soil $+50 \%$ additive. The blends were evaluated according to their physical properties (Atterberg limits, grain size, and compaction) and mechanical behavior (direct shear test). The results for the compositions indicated that the larger the proportion of ceramic residue and sand, the higher the values of the apparent dry density and the lower the optimum moisture; and, in particular, the addition of ceramic residue had a positive effect on the mechanical results, clearly demonstrated by the increase in the cohesion of the $10 \%$ blend. These results validate the potential of the residue for use in road work, in addition to the environmental benefits, either as a disposal alternative of an environmental liability or as a form of minimizing natural resource extraction.
\end{abstract}

Keywords: ceramic residue, clayey soil, shear strength

\section{INTRODUCTION}

The production of red ceramics (bricks and tiles) is an important economic activity in the Brazilian industrial scenario, due to its fundamental role in the activity of the national construction market. It is a productive sector with many ceramics industries in different states that produces about 2.5 billion pieces annually.

In the state of Amazonas, production is concentrated in the counties of Manacapuru and Iranduba, both within the Manaus Metropolitan Area. Iranduba is traditionally held to be the principal pottery hub, with a total of 25 potteries active and members of the Amazonas State Potters Association.

Iranduba is responsible for about $80 \%$ of the total production of red ceramics in the State of Amazonas, producing approximately 10 million bricks per month. At the same time, the Ceramics Hub fills, on average, $80 \%$ of the demand of the Amazonian construction industry, generating approximately 2,000 direct and indirect jobs in the county, covering a total of 6,000 workers, between service providers and suppliers.

However, there is also great concern over the destination of the tailings, especially those produced after the burning stage, coming from ceramic material (coating, tiles, bricks, and so forth) with faults or imperfections. The volume of the material discarded represents, on average, $3.0 \%$ of all national ceramic tile production. Correlating this percentage with actual production, an enormous amount of this by-product is currently available in deposits, in useless landfills, causing severe environmental damage.

Also, the county of Manaus suffers from a historic shortage of stone material, with surface soils inadequate for paving (due to fine grain size) and excessive costs due to the distances involved in the acquisition and transportation of better quality inputs [1]. However, the literature amply illustrates stabilization as a process to improve specific soil properties. The process can be carried out in two ways: mechanical stabilization, obtained mainly by the addition of granular material to the fine soil, or chemical stabilization, per- 
formed through the addition of chemical additives, both are indicated as techniques which improve the soils usually unsuitable for pavement construction [2].

This problem raises the need for research on technical, economic and environmental alternatives, theme of the present study, that is, the addition of the ceramic residue from Iranduba potteries to the clayey soil (abundant in the superficial layer of the regional subsoil), commonly used in Manaus in the pavement base. This process will contribute to the reduction of environmental impacts caused by its improper disposal and allow the use of a technically inadequate soil in paving works.

The purpose of this study, then, is to analyze the geotechnical behavior of clayey soil typical to Manaus when stabilized with ceramic residue from the Iranduba Pottery Hub, as well as to propose a destination for this environmental liability.

\section{MATERIALS AND METHODS}

\subsection{Soil}

Considering the predominance of the clay fraction in the surface layer of the subsoil of Manaus, this texture was selected initially, through visual and tactile analysis. These deformed samples were collected from the surface layer near the Institute of Exact Sciences buildings at the Federal University of Amazonas (UFAM), Coroado, in eastern Manaus.

Samples were prepared (Figure 1) in accordance with the recommendations of NBR 6457 (1986). They were then characterized in the Soil Laboratory of the UFAM Geotechnics Group as to grain size (ABNT NBR 7181, 1988), liquid limit (ABNT NBR 6459, 1984), plasticity limit (ABNT NBR 7180, 1984), density of soil solids (ABNT NBR 6508, 1988) and compaction (ABNT NBR 7182, 1988).

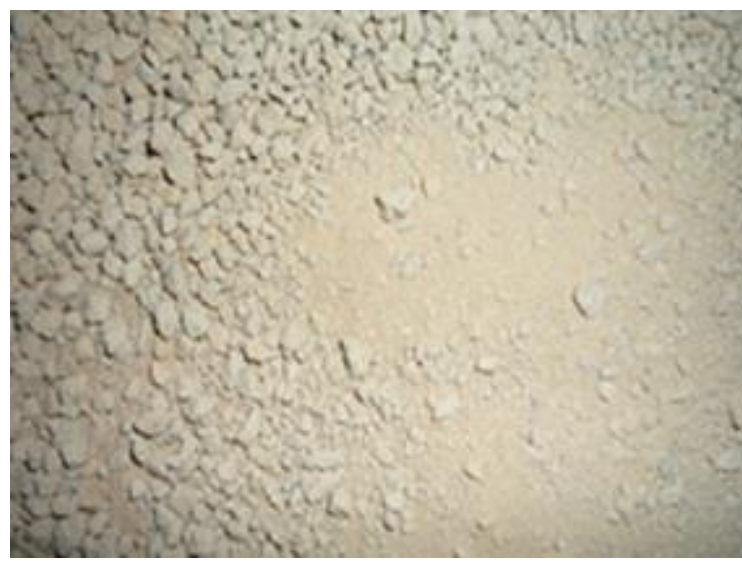

Figure 1: Natural clayey soil

\subsection{Residual sand and ceramic residue}

As reference material, residual sand (Figure 2) marketed in Manaus and normally used in pavement construction was chosen. It was characterized according to grain size (ABNT NBR 7181, 1988) and density of soil solids (ABNT NBR 6508, 1988). 


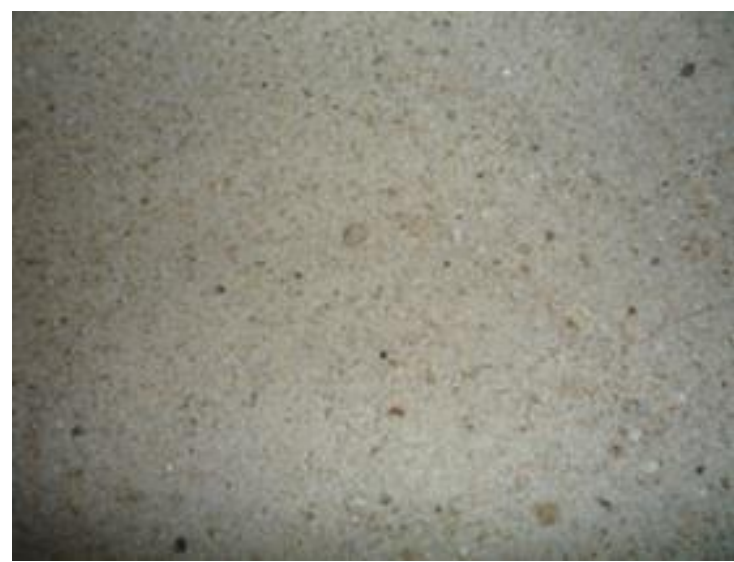

Figure 2: Residual Sand

The alternative material came from the Iranduba Pottery Hub. The samples consist of residue from bricks discarded because they failed quality control. In this study, the ceramic powder (Figure 3) used was a product of the reduction in grain size from 12.5 to $4.8 \mathrm{~mm}$, from 4.8 to $2 \mathrm{~mm}$ and less than $2 \mathrm{~mm}$. This grouping was achieved by ball milling in the Los Angeles abrasion tester, consisting of a steel drum and twelve metal spheres, each weighing from 400 to $450 \mathrm{~g}$ and with a diameter of about $48 \mathrm{~mm}$. In this case, the material selected passed through a $1.2 \mathrm{~mm}$ sieve after 500 revolutions at a speed of 30 to $33 \mathrm{rpm}$. It was analyzed for grain size (ABNT NBR 7181, 1988) and density of soil solids (ABNT NBR 6508, 1988).

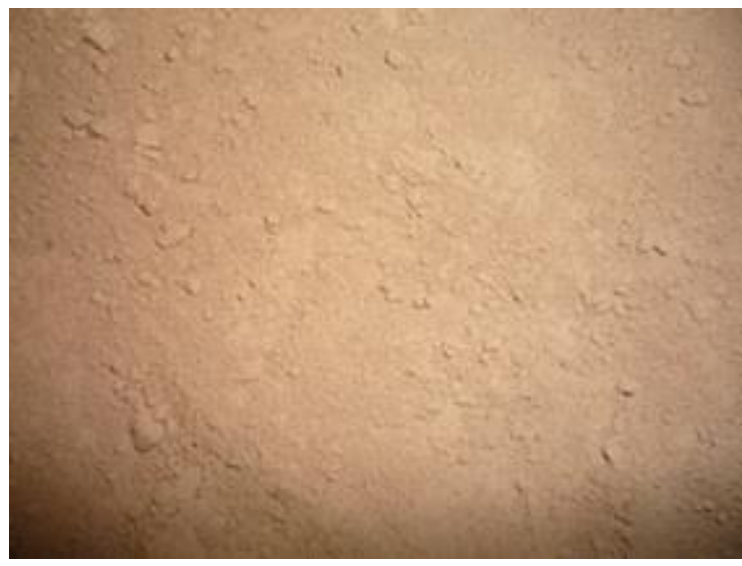

Figure 3: Ceramic powder

\subsection{X-Ray Diffraction}

The SHIMADZU XRD-6000 was used for the mineralogical identification, with CoK $\alpha$ radiation, graphite monochromator and operated at $40 \mathrm{kV}$ and $25 \mathrm{~mA}$. The samples were ground and then deposited on aluminum foil and subjected to diffraction analysis (XRD), over the $2 \theta$ range of $5^{\circ}$ to $60^{\circ}$, at $0.02^{\circ}$ intervals.

\subsection{Soil stabilized with ceramic powder}

The blends of natural soil and ceramic residue (at 10\%, 30\%, and 50\%) were compared to the reference blend composed of natural soil and residual sand (at 10\%, 30\%, and 50\%). Given the ascending order of addition of the material to the blend, SRC10, SRC30, and SRC50 referred to soil-residue blends, and SAR10, SAR30 and SAR50 to soil-sand blends. The dosages of these grain size arrangements were calculated regarding dry density, and the tests were carried out using the following methodology:

1) Addition of ceramic powder or sand to the natural soil, followed by homogenization of the mixture;

2) Addition of water to the mixtures for compaction, liquidity limit and plasticity limit tests;

3) Molding of the samples according to the compaction parameters (maximum dry density and optimum moisture) for Intermediate Proctor energy, for the direct shear tests, controlling for degree of compac- 
tion. The mass of specimens for the direct shear tests were calculated according to (1). In Figure 4 we see the mold used for compaction of these samples.

$$
\begin{aligned}
& \mathrm{m}=\mathrm{GC} \cdot \rho_{\mathrm{dmáx}} \cdot\left(\mathrm{w}_{\mathrm{ot}}+1\right) \cdot \mathrm{V}_{\text {molde }} \\
& \mathrm{m}=\text { mass to be compacted, }[\mathrm{g}] \\
& \mathrm{GC}=\text { degree of compaction at } 100 \% \\
& \rho d m a x=\text { maximum dry density, }\left[\mathrm{g} / \mathrm{cm}^{3}\right] \\
& \text { wot = optimum moisture, }[\%] \\
& \text { Vmold = sample volume, }\left[\mathrm{cm}^{3}\right]
\end{aligned}
$$

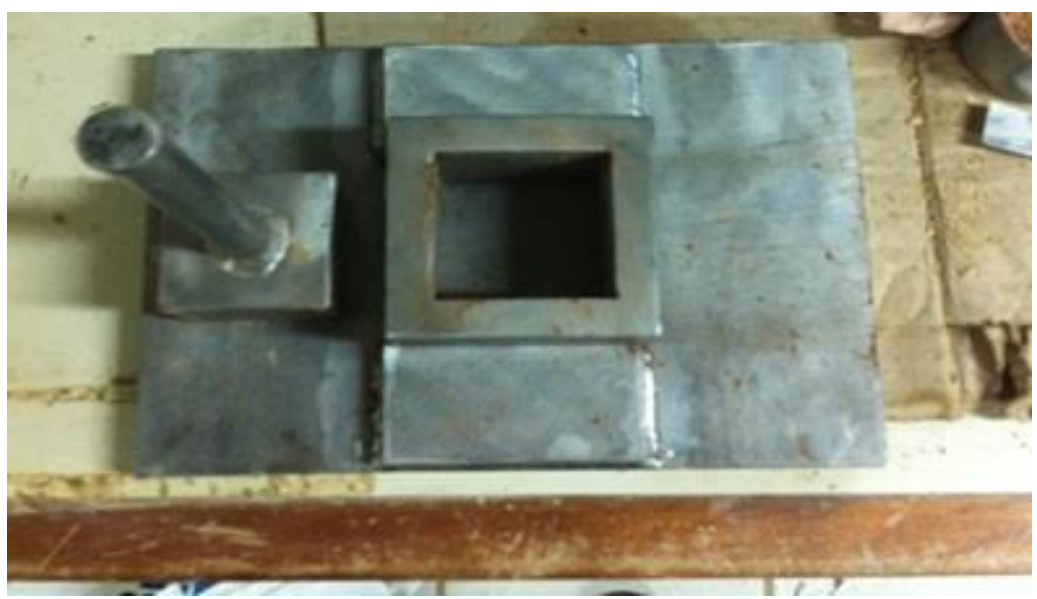

Figure 4: Mold for sample compaction

The samples were molded and tested for direct shear resistance to controlled deformation, as recommended by the American Society for Testing and Materials (ASTM D 3080, 2011). Samples were subjected to standard tensile strengths of 50,100, 150 and $200 \mathrm{kPa}$ at a rate of $1 \mathrm{~mm} / \mathrm{min}$ to obtain the shear stresses associated with their respective normal stresses and thus by the Coulomb rupture criterion, determine the cohesion parameters and angle of internal friction.

\section{RESULTS AND DISCUSSION}

\subsection{Materials}

X-ray diffraction analysis showed that the natural soil (Figure 5) contained quartz (Q), kaolinite (K), halloysite $(\mathrm{Hl})$, goethite $(\mathrm{Gt})$, anatase $(\mathrm{An})$ and hematite $(\mathrm{Ht})$. This result characterizes the mineralogy typical of the soils of the Manaus region, emphasizing its nature as a kaolinite soil. The physical properties of the material showed a density of soil solids of $2,571 \mathrm{~g} / \mathrm{cm}^{3}$ and Atterberg limits of 83 (LL) and 41 (LP). These results indicate its geotechnical classification as having very high plasticity, according to [3], in contrast, however, with its kaolinite mineralogy. As for texture, the distribution is shown in Figure 6, where it can be observed that this soil can be considered as clayey (76.08\%), with a predominance of the fine fraction $(84.1 \%)$. 


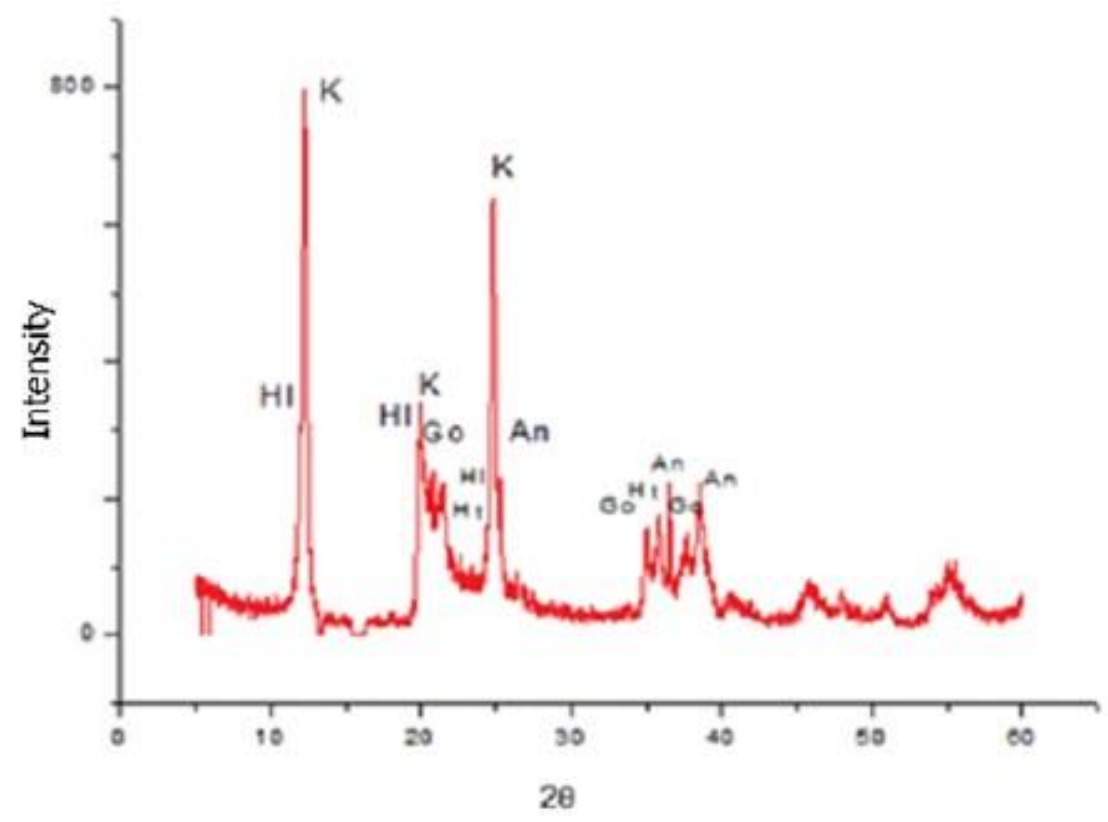

Figure 5: Diffractogram of the natural clayey soil

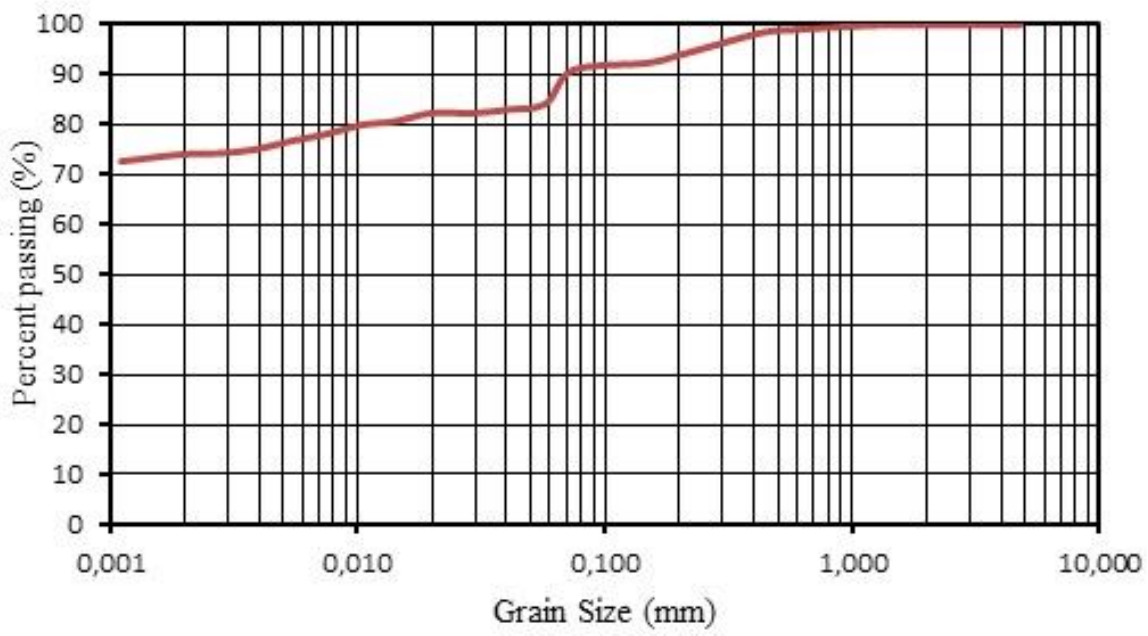

Figure 6: Grain size distribution curve of the natural soil.

The combined analysis of the consistency and grain size distribution indices classified the natural soil by USCS (Figure 7) and TRB (Figure. 8), as MH (inorganic silt of high plasticity) and A-7-5 (47), respectively. This material is unsuitable for paving, according to both classifications. This result, with respect to the USCS, has brought to light a disagreement with the grain size distribution analysis, since it indicated a silty soil and a clayey soil texture. This contradictory behavior is due to the way the consistency limits are implemented, since they were originally formulated for temperate soils, being therefore unsuitable for tropical soils. Hence the great difficulty, in such experiments, in disaggregating the lumps inherent to this type of grain size distribution, caused by additional "cementing" originating from the presence of iron oxides and hydroxides and aluminum. 


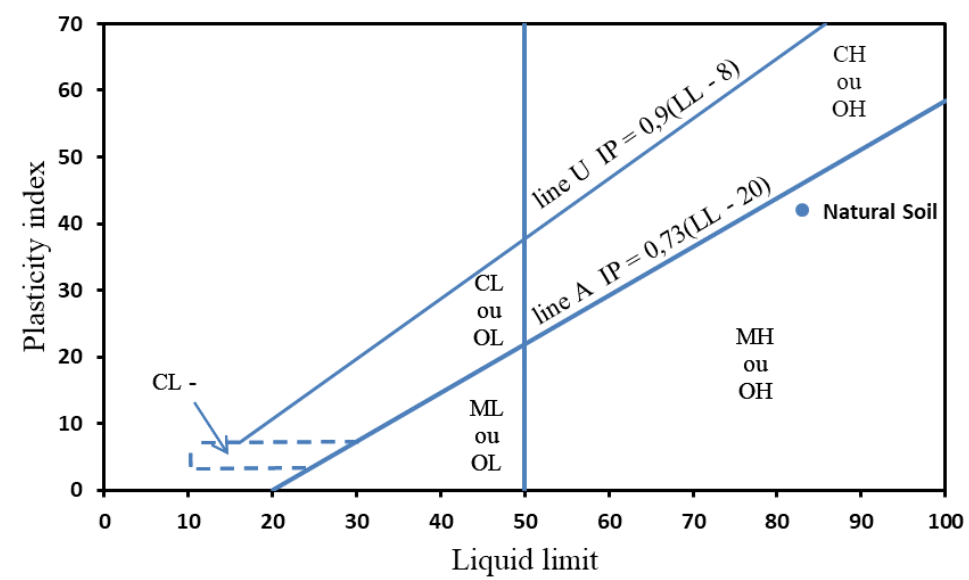

Figure 7: Natural soil classification in the USCS Plasticity Chart

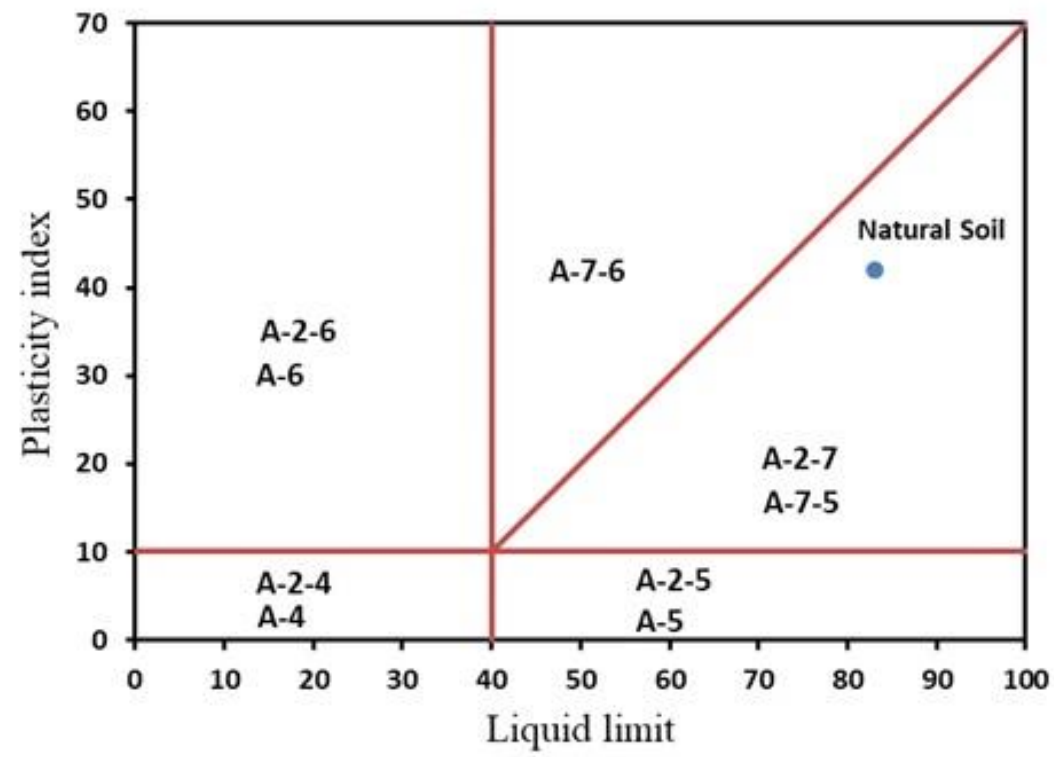

Figure 8: Natural soil classification in the TRB Plasticity Chart

In the ceramic residue sample, the minerals quartz $(\mathrm{Q})$ and halloysite $(\mathrm{H} 1)$ were identified, as may be observed in Figure 9. This last mineral has its origin in the burning of kaolinite during the manufacturing process of the ceramic material. In the sand sample, the X-ray diffraction showed: quartz $(\mathrm{Q})$ and rutile $(\mathrm{R})$ (Figure 10). The presence of rutile, a mineral typically found in igneous rocks, clearly indicates that the sand was collected on a river bank. Therefore, it was transported and deposited. The density of the sand particles and the ceramic residue was $2.68 \mathrm{~g} / \mathrm{cm}^{3}$ and $2.72 \mathrm{~g} / \mathrm{cm}^{3}$, respectively. The distribution of the texture of these materials is shown in Figure 11, demonstrating that ceramic powder can be considered clayey-sandy silt, with a predominance of the fine fraction $(68.0 \%)$. The residual sand can be seen as characteristic of this grain size fraction $(98.97 \%$ ) and presented a uniformity coefficient $\mathrm{UC}=2.5$ and curvature coefficient $\mathrm{CC}=0.9$, that is, well-graded granular material and a discontinuous curve, respectively [3]. 


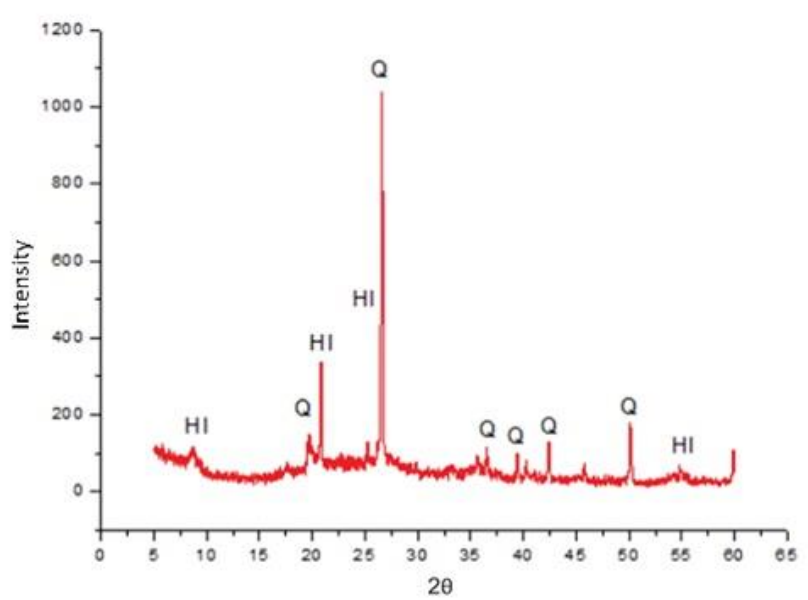

Figure 9: Diffractogram of the ceramic residue

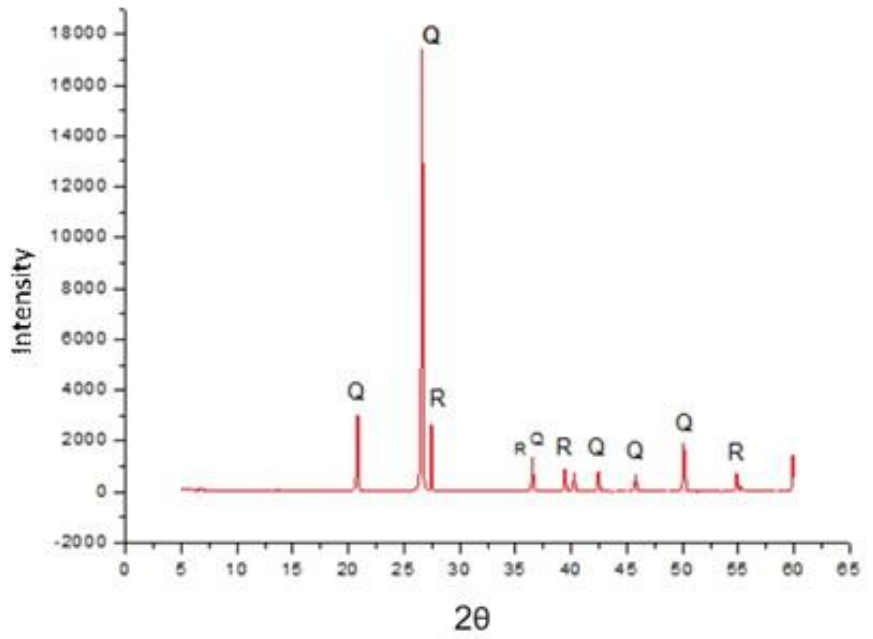

Figure 10: Diffractogram of the ceramic residue

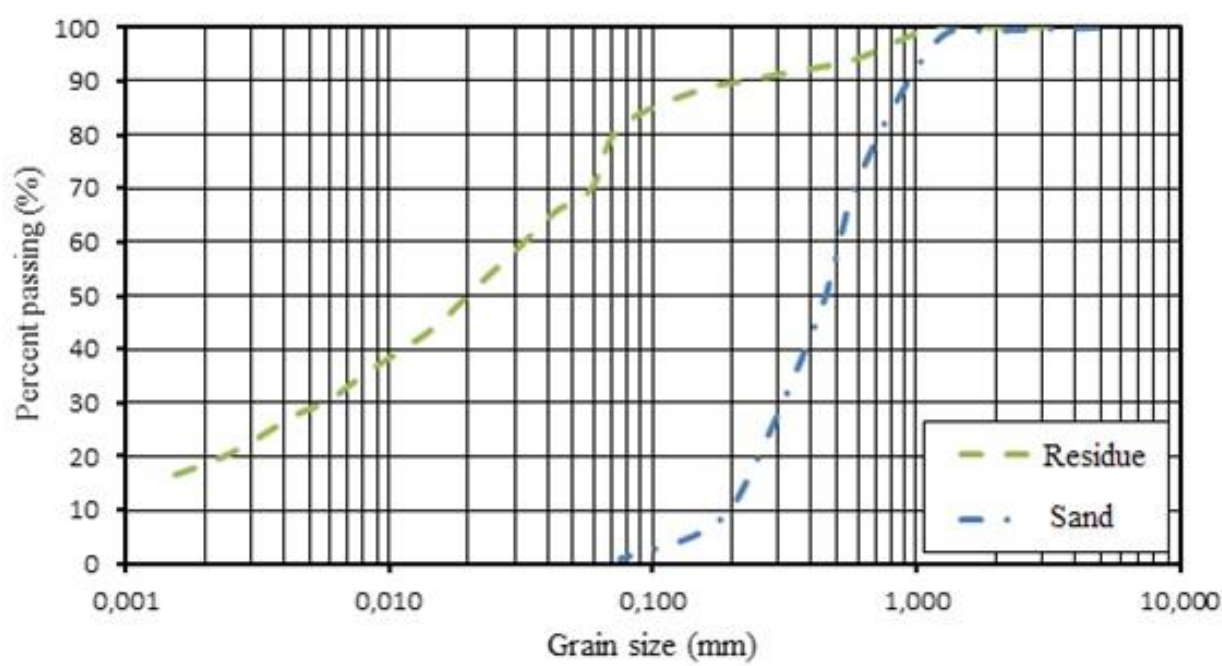

Figure 11: Grain size distribution curves of the ceramic residue and residual sand. 


\subsection{Mixtures}

Figure 12 (a), (b) and (c) displays the results with respect to the Atterberg limits and the Plasticity Index of the soil-ceramic residue (SRC), soil-residual sand (SAR) compositions for the natural soil: (a) for SRC10, the LL value did not vary, LP decreased and IP increased; (b) for SRC30, the LL value decreased and the LP remained practically constant; (c) for SRC50, the LL value obtained was 60, similar to the SRC30 blend, whereas the LP decreased to 34, in contrast to the other compositions with ceramic material; (d) for SAR10, the addition of sand reduced the Atterberg limits and the Plasticity Index; (e) the SAR30 and SAR50 compositions presented similar values for liquidity and plasticity limits; and (f) in general, the set of blends surveyed indicated a decrease for the IP.
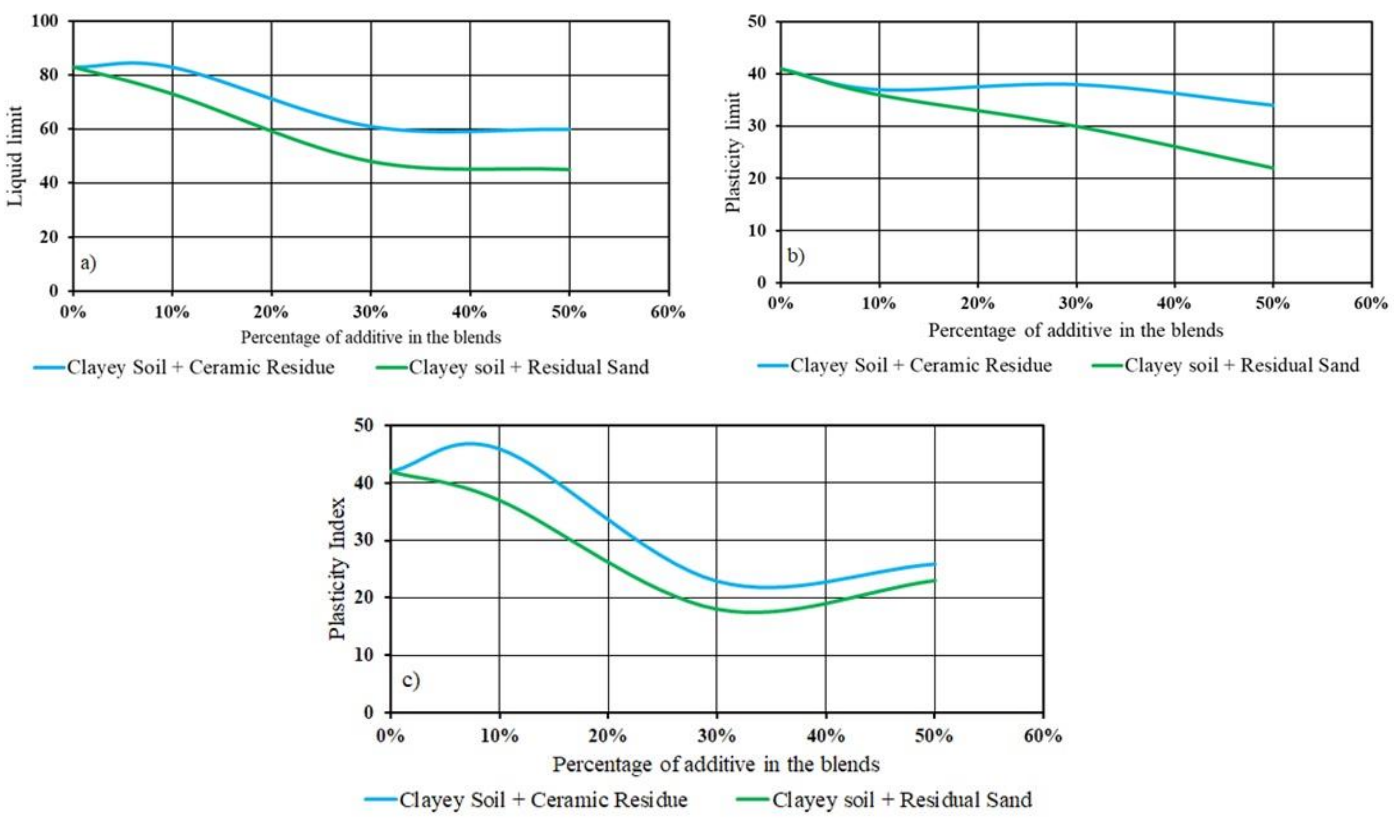

Figure 12: (a) Liquidity limit, (b) Plasticity limit and (c) Plasticity index of blends

Results for the compositions shown in the Plasticity Chart, according to the USC system , Figure 13 (a), and the TRB classification, Figure 13 (b), are: (a) CH and A-7-5 (49) for SRC10; (b) MH and A-7-5 (25) for SRC30; (c) MH and A-7-5 (24) for SRC50; (d) MH and A-7-5 (37) for SAR10; (e) ML and A-7-5 (14) for SAR30; and (f) CL and A-7-6 (5) for SAR50. Hence, in both classifications, the blends were found to be inappropriate for base and subbase layers of the pavement.
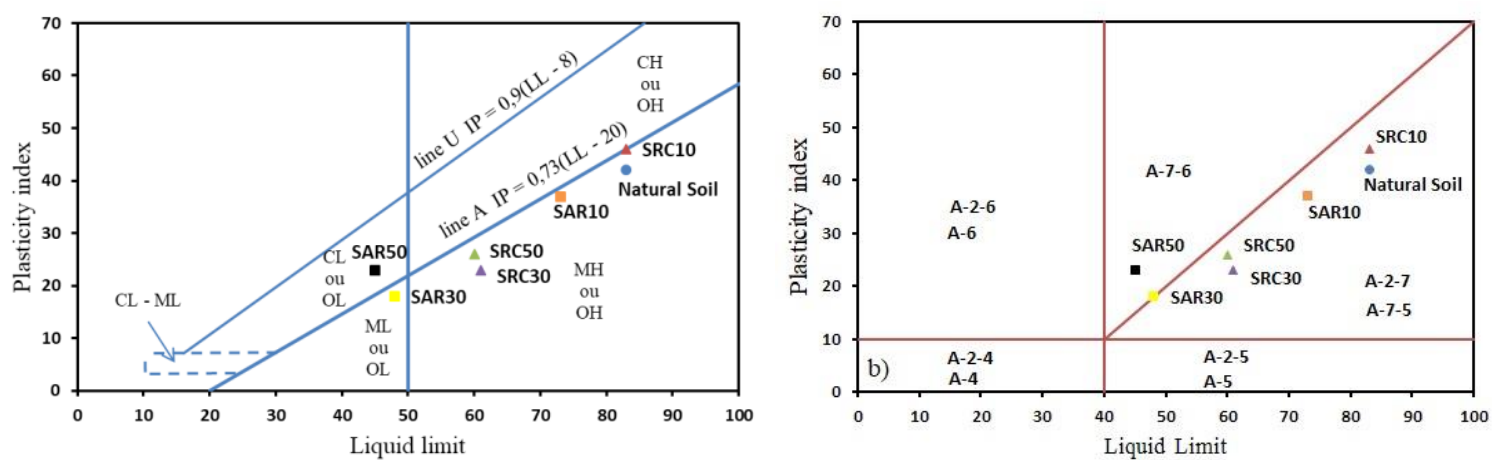

Figure 13: Classification of blends in the Plasticity Chart, according to (a) the USC and (b) the TRB systems

The parameters from the compaction tests, presented in Figure 14, led to the preparation of samples with degrees of compaction between 97 and 100\%. The data presented in the figure indicate that the increased proportion of ceramic residue and residual sand raised the maximum dry density and decreased the optimum moisture of the compositions under study, thus optimizing compaction in the field. Also interesting are the $\mathrm{R}^{2}$ values ranging from 0.93 to 0.99 


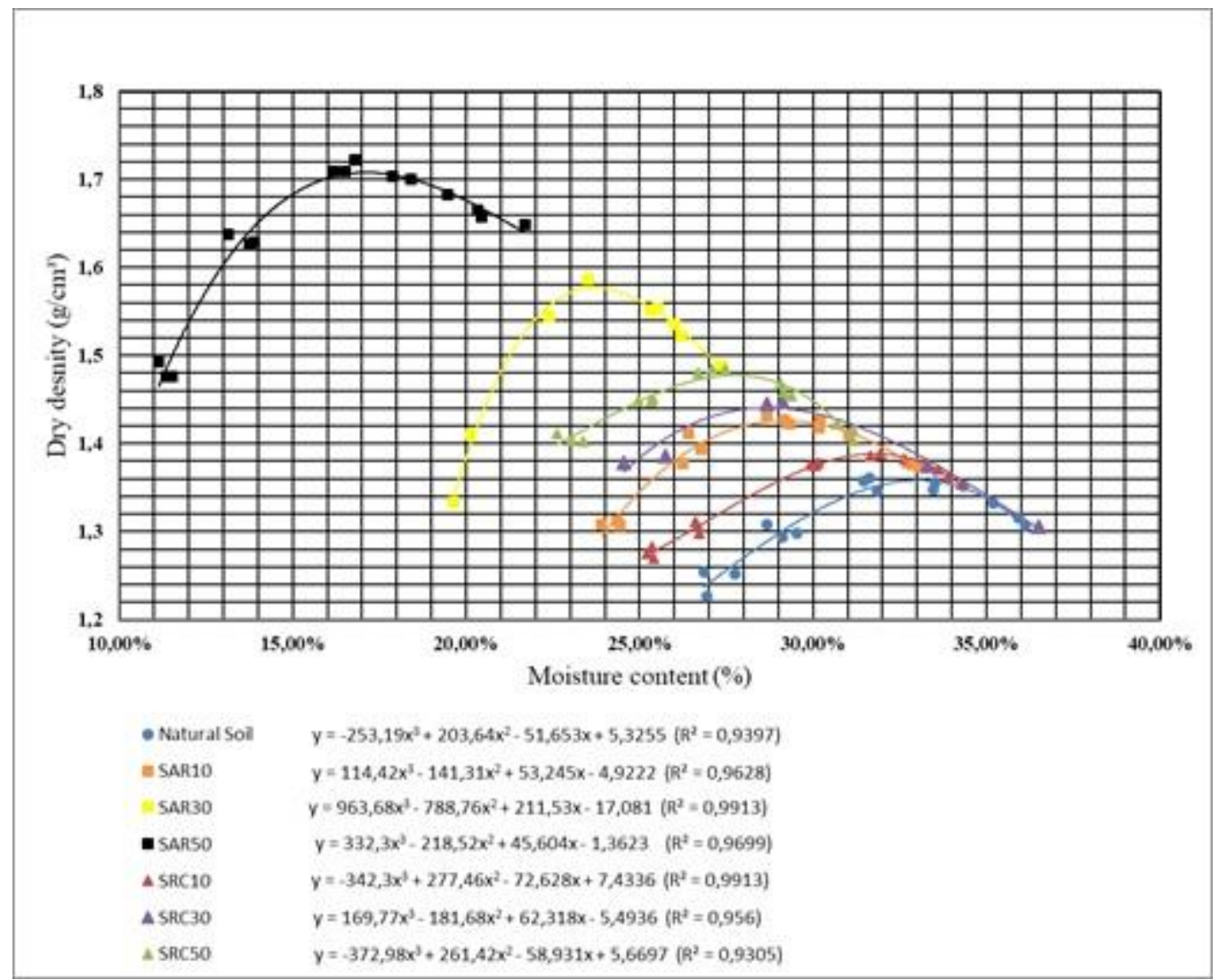

Figure 14: Compaction curves for the natural soil and blends.

The samples molded and tested in the direct shear press gave the paired values for shear stress rupture vs. normal stress. Applying the Coulomb criterion, their respective equations were obtained (Figure 15), which indicated optimum values for the $\mathrm{R}^{2}$ coefficient (0.98 to 0.99), as well as the determination of cohesion and angle of friction for each composition (Figure 16). Normal stresses of 50, 100, 150 and $200 \mathrm{kPa}$ were employed with the following results: the addition of $10 \%$ ceramic waste to the soil- produced a substantial gain in cohesion. In percentage terms, the increase was about $65 \%$, which illustrates the potential of this material for improving the mechanical characteristics of the clayey soil commonly used in the sublayers of the pavements in the county of Manaus, Amazonas. The insertion of 30\% of this by-product led to a decrease of cohesion when compared to the SRC10 blend, and at 50\%, no gain was indicated, which suggests there is an optimum content with regard to cohesion. As for the angle of friction, the blends with $10 \%$ and $30 \%$ residue produced a decrease and an increase at 50\%. Unlike the compositions with environmental liability, soil-sand compositions produced a decrease in cohesion, in proportion to the addition of fine granular soil. Natural soil presented a value of $89 \mathrm{kPa}$, which decreased to $23.5 \mathrm{kPa}$ at $50 \%$ (SAR50), a reduction, in percentage terms, of approximately $73.6 \%$. The soil and the SAR10 composition produced angles of friction of $34.44^{\circ}$ and $27.2^{\circ}$, respectively. It is important to note that the 50\% sand (SAR50) mixture presented a result close to its natural state. Thus, it did not represent any additional gain. 


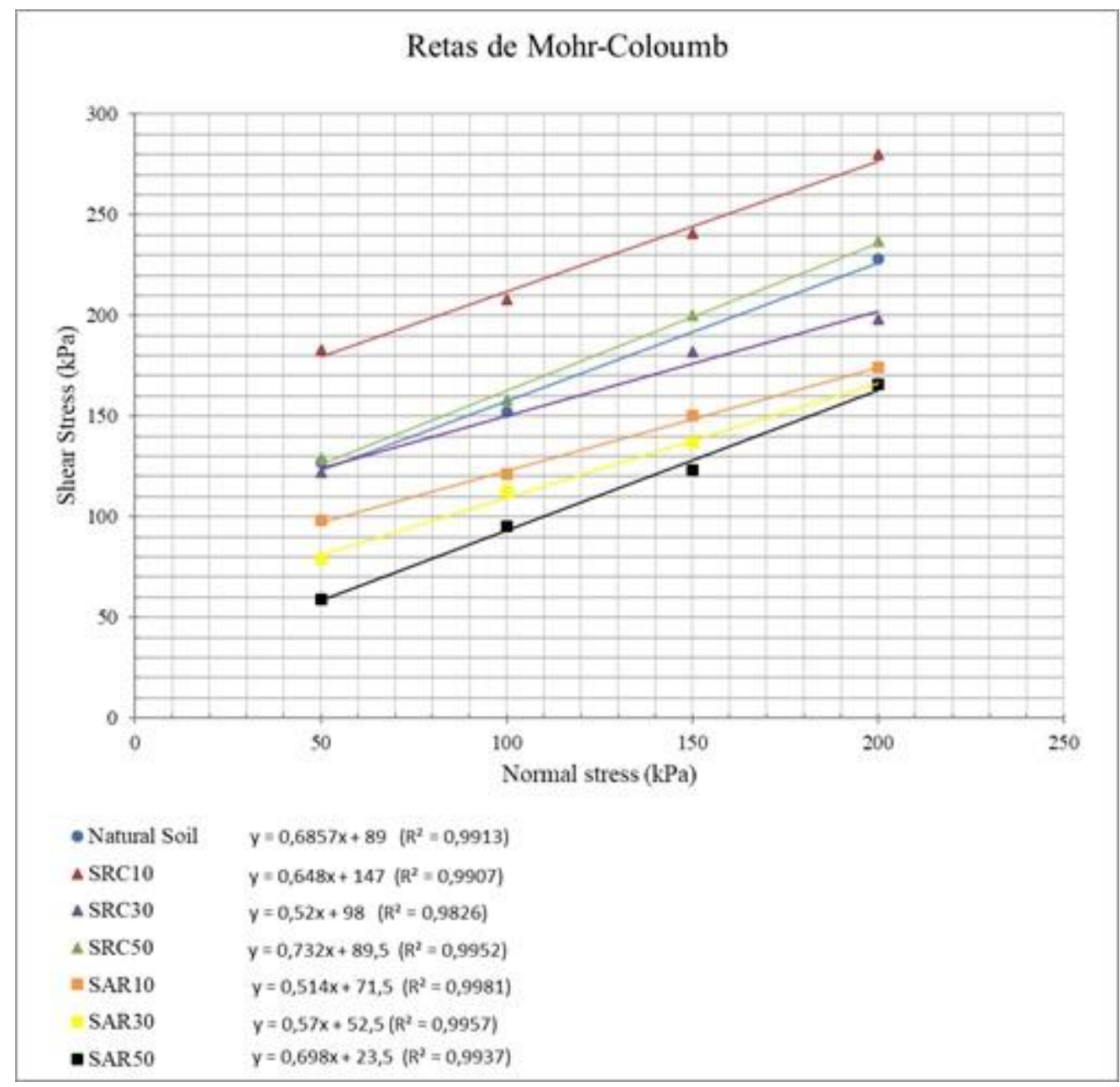

Figure 15: Coulomb criterion for natural soil and compositions
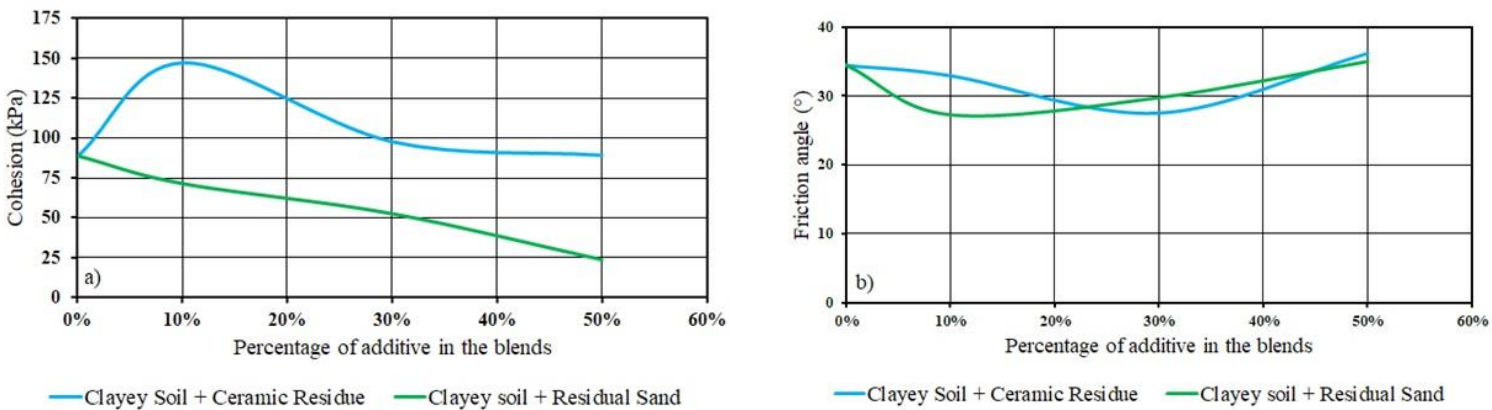

Figure 16: (a) Cohesion and (b) angle of friction, function of the additive \%

SHALABI, et al. [4] studied the addition of steel slag for mechanical stabilization of an expansive clayey soil. They evaluated the effect of the following proportions on the mixture: $0 \%, 15 \%, 30 \%$ and $100 \%$ of steel slag in the parameters of shear strength. The results show that as the steel slag content increases, the cohesion intercept decreases, and the angle of internal friction increases. The increase in angle of internal friction and decrease in cohesion intercept with the increase in steel slag content is due to the frictional nature (the grains are angular and rough) of the steel slag. DAFALLA [5] studied the effects of clay addition on artificial mixtures of clay and sand by means of the direct shear test. The proportions used were: $5 \%, 10 \%$ and $15 \%$ of clay. It was concluded that the increase of the clay content can help increase the cohesion to 5\% and $10 \%$ of clay. Prabakar, et al [6] evaluated the influence of fly ash addition on three different soil types according to shear strength. The results indicated the increase of cohesion for low plasticity soils. However, in high plasticity soils the addition of fly ash reduced cohesion and increased the angle of friction. Comparing 
with the results shown previously, the ceramic powder appears as a material with great potential to increase the shear strength, especially with the addition of $10 \%$.

\section{CONCLUSIONS}

The results lead to the following inferences: the natural material was shown to be soil characteristic of the urban area of the county of Manaus, Amazonas, Brazil, according to both the predominant grain size distribution of the clay fraction, and the mineralogy identified by X-ray diffraction. The data from the compaction test indicated that a larger proportion of sand or ceramic residue reduced the optimum moisture and raised the maximum dry density of the compositions, improving compaction in the field. Among the formulations proposed, the arrangement with $10 \%$ ceramic powder was superior to the others in mechanical behavior, as can be seen by the substantial increase in cohesion. The data also indicated an "optimum" content to maximize gains. This study presented ceramic waste as an alternative material to be used in regional road works, also suggesting a final destination for the ceramic waste as an environmental liability, and an environmental solution that reduces the extraction of natural raw material to a minimum.

\section{BIBLIOGRAPHY}

[1] FROTA, C. A., NUNES, F. R. G., SILVA, C. L., et al., "Mechanical performance of asphalt mixtures composed of synthetic calcinated clay aggregates", Cerâmica, v. 53, pp. 255-262, Sep. 2007.

[2] PETRY, T. M., LITTLE, D. N., "Review of stabilization of clays and expansive soils in pavements and lightly loaded structures- History, practice and future”, ASCE Journal of Materials in Civil Engineering, v.14, pp.447-460, 2002.

[3] DAS, B. M., Principles of Geotechnical Engineering. 6 ed., Boston, PWS, 2005.

[4] SHALABI, F. I., ASI I. M., QASRAWI, H. Y., "Effect of by-product steel slag on the engineering properties of clay soils", Journal of King Saud University - Engineering Sciences, v. 29, pp. 395-399, Sep. 2016.

[5] DAFALlA, M. A., "Effects of Clay and Moisture Content on Direct Shear Tests for Clay-Sand Mixtures”, Advances in Materials Science and Engineering, v. 2013, pp. 1-8, 2013.

[6] PRABAKAR, J., DENDORKAR, N., MORCHHALE, R. K., "Influence of fly ash on strength behavior of typical soils", Construction and Building Materials, v. 18, pp. 263-267, May, 2004.

\section{ORCID}

Matheus Pena da Silva e Silva

Lucas Fernandes Santos

Antônio Cleiton Lopes da Silva

Consuelo Alves da Frota https://orcid.org/0000-0002-7009-4458

https://orcid.org/0000-0002-9581-4028

https://orcid.org/0000-0001-7343-350X

https://orcid.org/0000-0002-1766-2823 